\title{
Upregulated NTF4 in colorectal cancer promotes tumor development via regulating autophagy
}

\author{
ZHOU YANG $^{1 *}$, YUSHENG CHEN $^{1 *}$, XIYI WEI $^{2^{*}}$, DEJUN WU $^{1}$, ZHIJUN MIN $^{1}$ and YINGJUN QUAN ${ }^{1,3}$ \\ ${ }^{1}$ Department of General Surgery, Shanghai Pudong Hospital, Fudan University Pudong Medical Center, Shanghai 201399; \\ ${ }^{2}$ First Clinical Medical College of Nanjing Medical University, Nanjing, Jiangsu 210029; \\ ${ }^{3}$ Tongren Hospital, Shanghai Jiao Tong University School of Medicine, Shanghai 201399, P.R. China
}

Received October 1, 2019; Accepted February 11, 2020

DOI: $10.3892 / \mathrm{ijo} .2020 .5027$

\begin{abstract}
Autophagy plays a key role in colorectal cancer (CRC) development and reduces the sensitivity of CRC cells to treatment. The present study reported a novel tumor-suppressive role for autophagy, which was demonstrated to be regulated through the novel oncogene neurotrophin-4 (NTF4). NTF4 was significantly overexpressed in tumor tissue compared with non-tumor mucosa, and the upregulation of NTF4 in CRC was associated with poor overall survival and advanced TNM stage. The genetic knockdown of NTF4 using short hairpin RNA in CRC cells prevented epithelial-to-mesenchymal transition and activated autophagy; this was regulated through the interaction between autophagy-associated gene 5 (Atg5) and the mitogen-activated protein kinase pathway. In addition, the knockdown of NTF4 inhibited cell invasion, migration, proliferation and colony formation, and promoted cell cycle arrest. Treatment of the cells with the autophagy inhibitor chloroquine (CQ) rescued these functions and promoted cell invasion, migration, proliferation and colony formation. Finally, the knockdown of NTF4 inhibited the growth of subcutaneous xenografts in Balb/c-nu mice. In conclusion, these findings suggested that NTF4 may be a diagnostic marker associated with the overall survival and progression of patients with CRC. NTF4 was found to promote tumorigenesis and $\mathrm{CRC}$ development through autophagy regulation.
\end{abstract}

Correspondence to: Dr Yingjun Quan or Dr Zhijun Min, Department of General Surgery, Shanghai Pudong Hospital, Fudan University Pudong Medical Center, 2800 Gongwei Road, Huinan, Pudong, Shanghai 201399, P.R. China

E-mail: qyjasmine@126.com

E-mail: minzhijun@126.com

*Contributed equally

Key words: neurotrophin-4, colorectal cancer, epithelial-to-mesenchymal transition, autophagy, mitogen-activated protein kinase pathway

\section{Introduction}

Colorectal cancer (CRC) is a common malignant tumor of the digestive tract, with an estimated one million people diagnosed annually and a mortality rate of $\sim 33 \%$ (1). Although the early symptoms of CRC are difficult to detect, tumor progression and metastasis often presents with symptoms such as changes in stool habits, hematochezia and emaciation (2). Current treatment regimens for CRC include surgery, radiotherapy and chemotherapy; however, surgery is largely ineffective for patients with advanced-stage disease and the side effects of radiotherapy and chemotherapy are severe, with chemoresistance often posing a major challenge $(3,4)$. Thus, there is an urgent need to identify novel oncogenes that may be driving CRC tumorigenesis, which may serve as effective diagnostic markers and therapeutic targets to facilitate the diagnosis of early-stage CRC and block tumor development. Neurotrophin-4 (NTF4) belongs to the family of neurotrophic factors (NTFs), which are most commonly known for their roles in the nervous system $(5,6)$. Previous studies have observed that other NTFs, and their corresponding receptors, are associated with breast and gastric cancer development (6,7); however, little is known on the role of NTF4 in this process. Our previous study demonstrated that NTF4 was upregulated in patients with CRC, and bioinformatics analysis found NTF4 to be associated with tumor development (8). However, the specific mechanisms underlying the role of NTF4 in CRC remain largely unknown.

Epithelial-to-mesenchymal transition (EMT) is a crucial process that enables cancer cells to acquire invasive and metastatic properties. Tumor cells that undergo EMT are characterized by the loss of epithelial markers and the acquisition of mesenchymal properties, accompanied by changes in various other molecular markers, including the downregulation of epithelial markers, such as E-cadherin and $\beta$-catenin, and the upregulation of mesenchymal markers, such as vimentin and $\mathrm{N}$-cadherin (9). Our previous study demonstrated that EMT was instrumental in promoting CRC invasion and progression (10).

Autophagy is a phagocytic process, whereby cytoplasmic proteins or organelles are phagocytosed into vesicles and fused with lysosomes to form autophagic lysosomes, or autophagolysosomes (11). These autophagolysosomes degrade the contents of the lysosomes in response to the metabolic requirements 
of the cells and provide nutrients to promote the renewal of organelles. The majority of malignant tumors are positively or negatively regulated by autophagy at some point during the initiation, development or metastasis of tumors; for example, it was previously reported that autophagy inhibited programmed cell death to inhibit cancer cell growth (12), whereas another study reported that autophagy improved the tolerance of cancer cells to stress and promoted their survival (13). Most previous studies on CRC have observed that autophagy promotes both the initiation and development of cancer, and reduces the sensitivity of cancer cells to treatment $(14,15)$. Thus, the present study aimed to investigate the role of the novel oncogene, NTF4, as a regulator of autophagy in CRC.

\section{Materials and methods}

Patient samples. The present study was approved by the Ethics Committee of Shanghai Pudong Hospital and written informed consent was obtained from all participants. A total of 74 CRC specimens and 4 normal healthy colon tissue samples were collected from patients between July 2016 and July 2018 (Table I). Eligible CRC patients should have received adjuvant chemotherapy or radiotherapy prior to surgery, and patients with additional cancer diagnoses were excluded from the study. All patients were classified according to the TNM staging system (8th edition; https://cancerstaging.org). Postoperative adjuvant therapies were performed according to the standard schedule and doses.

Immunohistochemistry (IHC). IHC staining was performed on paraffin-embedded sections obtained from the patient tissues. The sections were subsequently deparaffinized in xylene and rehydrated in a descending series of ethanol (100, 90, 80 and $75 \%$ ) for $3 \mathrm{~min}$ each, followed by heating in sodium citrate buffer for antigen retrieval. The sections were blocked in 5\% BSA (Beyotime Institute of Biotechnology) and incubated with a rabbit anti-NTF4 primary antibody (1:100; cat. no. 12297; ProteinTech Group, Inc.) at $4^{\circ} \mathrm{C}$ overnight. Following incubation with the primary antibody, the sections were incubated with a horseradish peroxidase (HRP)-conjugated anti-rabbit secondary antibody (1:200; cat. no. SA00001; ProteinTech Group, Inc.) for $1 \mathrm{~h}$ at room temperature. The slides were subsequently stained with 3,3'-diaminobenzidine and hematoxylin at room temperature for $5 \mathrm{~min}$, and visualized using an Olympus IX71 inverted microscope (Olympus Corporation) at a magnification of $\mathrm{x} 200$.

Cell lines and reagents. The human CRC cell lines HCT-116 and HT-29 were purchased from the American Type Culture Collection and cultured in RPMI-1640 medium supplemented with $10 \%$ FBS (Invitrogen; Thermo Fisher Scientific, Inc.) and maintained in a humidified atmosphere at $37^{\circ} \mathrm{C}$ and $5 \% \mathrm{CO}_{2}$. Cells were digested and passaged upon reaching $80 \%$ confluence. All cell lines were authenticated using STR profiling and all experiments were performed with mycoplasma-free cells.

Cell transfection. Three short hairpin RNAs (shRNAs) targeting NTF4 and a scramble (scr) control were cloned into the pLKO.1 lentiviral vector (Table II). The pLKO-1.
shRNA (sh)NTF4 plasmid, psPAX2 and PMG.2G were co-transfected into 293 cells to obtain the shNTF4 lentivirus using Lipofectamine ${ }^{\circledR} 3000$ reagent (Thermo Fisher Scientific, Inc.), according to the manufacturer's protocol. The shNTF4 lentiviral supernatant was subsequently harvested and used to infect HCT-116 and HT-29 cells at a multiplicity of infection of 25 . Infected cells were screened using puromycin $(5 \mu \mathrm{g} / \mathrm{ml})$ for $72 \mathrm{~h}$ and the expression levels of NTF4 in the cells were confirmed using western blotting.

The siRNAs were transfected into HCT-116 cells using Lipofectamine ${ }^{\circledR} 3000$ reagent, according to the manufacturer's protocol.

Reverse transcription-quantitative PCR (RT-qPCR) analysis. Total RNA was extracted using TRIzol ${ }^{\circledR}$ reagent (Beyotime Institute of Biotechnology), according to the manufacturer's protocol. Total RNA was reverse-transcribed into cDNA using the PrimeScript ${ }^{\mathrm{TM}} \mathrm{RT}$ reagent kit (Takara Bio, Inc.) at $37^{\circ} \mathrm{C}$ for $15 \mathrm{~min}$ and $85^{\circ} \mathrm{C}$ for $5 \mathrm{sec}$. qPCR $\left(95^{\circ} \mathrm{C}\right.$ for $30 \mathrm{sec} ; 95^{\circ} \mathrm{C}$ for $3 \mathrm{sec}, 60^{\circ} \mathrm{C}$ for $30 \mathrm{sec}$, for 40 cycles) was subsequently performed using the $\mathrm{SYBR}^{\circledR}$ Premix Taq $^{\mathrm{TM}}$ kit (Takara Bio, Inc.) and a Vii 7R real-time PCR machine (Applied Biosystems; Thermo Fisher Scientific, Inc.). The primers used for the qPCR are listed in Table III. Expression levels were quantified using the $2^{-\Delta \Delta \mathrm{Cq}}$ method (16) and normalized to the internal reference gene $\beta$-actin.

Western blotting. Total protein was extracted from the cells using RIPA lysis buffer with $1 \%$ phenylmethanesulfonyl fluoride and $1 \%$ DL-Dithiothreitol. Total protein was quantified using a bicinchoninic acid assay kit (Beyotime Institute of Biotechnology) and $20 \mu \mathrm{g}$ protein/lane was separated by $10 \%$ SDS-PAGE. The separated proteins were subsequently transferred onto PVDF membranes (Beijing Solarbio Science \& Technology Co., Ltd.) and blocked with 5\% BSA for $1 \mathrm{~h}$ at room temperature. The membranes were incubated with the following primary antibodies at $4^{\circ} \mathrm{C}$ for $12 \mathrm{~h}$ : Anti-NTF4 (1:1,000; ProteinTech Group, Inc.), anti-E-cadherin (1:1,000; cat. no. 20874; ProteinTech Group, Inc.), anti-N-cadherin (1:1,000; cat. no. 22018 ProteinTech Group, Inc.), anti-vimentin (1:1,000; cat. no. 10366; ProteinTech Group, Inc.), anti-Twist (1:1,000; cat. no. 25465; ProteinTech Group, Inc.), anti-Atg5 (1:1,000; cat. no. 10181; ProteinTech Group, Inc.), anti-Beclin-1 (1:1,000; cat. no. ab207612; Abcam), anti-p62 (1:1,000; cat. no. 56416; Abcam), anti-LC3B (1:1,000; cat. no. ab51520; Abcam), anti-phosphorylated (p)-p38 mitogen-activated protein kinase (MAPK; 1:1,000; cat. no. 4511; Cell Signaling Technology, Inc.), anti-p38 MAPK (1:1,000; cat. no. 8690; Cell Signaling Technology, Inc.), anti-phosphorylated extracellular signal-regulated kinase (p-ERK)1/2 (1:1,000; cat. no. 4370; Cell Signaling Technology, Inc.), anti-ERK1/2 (1:1,000; cat. no. 4695; Cell Signaling Technology, Inc.), anti-p-JNK (1:1,000; cat. no. 9255; Cell Signaling Technology, Inc.) and anti- $\beta$-actin (1:4,000; cat. no. 600008; ProteinTech Group, Inc.). Following incubation with the primary antibody, the membranes were incubated with anti-rabbit HRP-conjugated secondary antibodies (1:4,000; ProteinTech Group, Inc.) for $\sim 1 \mathrm{~h}$ at room temperature. Protein bands were visualized using ECL reagents (Thermo Fisher Scientific, Inc.) and an Omega Lum G machine (Aplegen). 
Table I. Clinical characteristics of patients.

\begin{tabular}{|c|c|}
\hline Characteristics & No. \\
\hline \multicolumn{2}{|l|}{ Tumor (T) stage } \\
\hline pT1 & 3 \\
\hline pT2 & 7 \\
\hline pT3 & 22 \\
\hline pT4 & 42 \\
\hline \multicolumn{2}{|l|}{$\mathrm{N}$ stage } \\
\hline No & 48 \\
\hline N1 & 22 \\
\hline N2 & 4 \\
\hline \multicolumn{2}{|l|}{ M stage } \\
\hline M0 & 70 \\
\hline M1 & 4 \\
\hline \multicolumn{2}{|l|}{ Age, years } \\
\hline$\leq 45$ & 24 \\
\hline$>45$ & 50 \\
\hline \multicolumn{2}{|l|}{ Sex } \\
\hline Male & 54 \\
\hline Female & 20 \\
\hline \multicolumn{2}{|l|}{ Tumor location } \\
\hline Right colon & 29 \\
\hline Left colon & 12 \\
\hline Transverse colon & 5 \\
\hline Sigmoid colon & 28 \\
\hline \multicolumn{2}{|l|}{ Histological grade } \\
\hline Well-differentiated & 70 \\
\hline Poorly differentiated & 4 \\
\hline \multicolumn{2}{|l|}{ Mucinous colloid type } \\
\hline No & 57 \\
\hline Yes & 17 \\
\hline
\end{tabular}

Co-immunoprecipitation (Co-IP). A total of $1 \times 10^{7}$ cells were harvested and lysed using NP-40 buffer. The lysates were pre-cleared using $20 \mu \mathrm{l}$ Protein A/G sepharose beads (Santa Cruz Biotechnology, Inc.) and subsequently centrifuged at $3,000 \mathrm{x} \mathrm{g}$ for $5 \mathrm{~min}$ at $4^{\circ} \mathrm{C}$ to obtain the supernatant. The pre-cleared lysate was incubated with $1 \mu \mathrm{g}$ anti-NTF4 polyclonal antibody for $12 \mathrm{~h}$ at $4^{\circ} \mathrm{C}$ with gentile rotation. Subsequently, $50 \mu 1$ Protein A/G sepharose beads were added to the lysate to capture the immunocomplex. Following incubation for $4 \mathrm{~h}$ at $4^{\circ} \mathrm{C}$, the beads were harvested by centrifugation at $3,000 \times \mathrm{g}$ at $4^{\circ} \mathrm{C}$ for $3 \mathrm{~min}$, and washed four times with NP-40 buffer. Elution of the proteins was conducted by adding 2X SDS loading buffer to the beads and boiling for $5 \mathrm{~min}$ at $95^{\circ} \mathrm{C}$ before subsequently performing western blotting, as previously described.

Immunofluorescence (IF) staining. Coverslips were placed horizontally on the bottom of a 6 -well plate and $1 \times 10^{6}$ cells were seeded/well and cultured at $37^{\circ} \mathrm{C}$ overnight. Cells were fixed with $4 \%$ paraformaldehyde for $10 \mathrm{~min}$ at room temperature and then permeabilized with $0.3 \%$ Triton $\mathrm{X}-100$ for $10 \mathrm{~min}$. The coverslips were blocked with 5\% BSA for $60 \mathrm{~min}$ and subsequently incubated with the following primary antibodies at $4^{\circ} \mathrm{C}$ overnight: Anti-E-cadherin (1:100), anti-NTF4 (1:100, cat. no. 12297; ProteinTech Group, Inc.), anti-LC3B (1:100, cat. no. ab51520; Abcam) and anti-Atg5 (1:100; cat.no. sc-133158; Santa Cruz Biotechnology, Inc.). The coverslips were washed three times with PBS for 5 min prior to being incubated with an Alexa 594-conjugated anti-rabbit secondary antibody or an Alexa 488-conjugated anti-mouse secondary antibody (1:400; cat. no. SA00013; ProteinTech Group, Inc.) for $1 \mathrm{~h}$ at $4^{\circ} \mathrm{C}$ in the dark. DAPI was used as a counterstain to label the nuclei. Stained cells were visualized and photographed using an Olympus IX71 inverted fluorescence microscope (Olympus Corporation) at a magnification of $\mathrm{x} 400$.

CRC and normal healthy tissues were embedded in paraffin and cut into $4-\mu \mathrm{m}$ sections. The sections were subsequently deparaffinized and blocked as previously described for IHC staining. Then, the sections were incubated with an anti-NTF4 primary antibody overnight at $4^{\circ} \mathrm{C}$, followed by sequential incubation with an HRP-conjugated secondary antibody for $1 \mathrm{~h}$ and a FITC-conjugated anti-HRP antibody (1:200; ProteinTech Group, Inc.) for $10 \mathrm{~min}$ at room temperature.

The sections were subsequently boiled in $1 \mathrm{mM}$ EDTA, followed by $15 \mathrm{~min}$ at a sub-boiling temperature to remove the antibodies that were incorporated into the tissues to re-stain for E-cadherin and Atg5. Similar to NTF-4 staining, anti-E-cadherin and anti-Atg5 antibodies were incubated with the slides. The sections were then incubated with HRP-conjugated anti-rabbit/mouse secondary antibodies and a Cy3-conjugated goat anti-HRP antibody or Cy5-conjugated goat anti-HRP antibody (1:200; cat. no. SA-00009, ProteinTech Group, Inc.). DAPI was used as a counterstain to label the nuclei. Stained sections were visualized and photographed using an Olympus IX71 inverted fluorescence microscope (Olympus Corporation) at a magnification of $\mathrm{x} 400$.

Transmission electron microscopy (TEM). A total of $1 \times 10^{5}$ cells were harvested for TEM, which was performed as previously described (14). Autophagosome formation was visualized using a Hitachi HT7700 transmission electron microscope (Hitachi High-Technologies Corporation).

Cell migration and invasion assays. Cell migration and invasion were analyzed using Transwell plates (pore size, $8 \mu \mathrm{m}$; BD Biosciences). Transwell plates (Corning Inc.) were coated with or without $55 \mu 1$ Matrigel (1:8; BD Biosciences) for the invasion or migration assay, respectively. Cells were plated in the upper chambers of Transwell plates in RPMI-1640 medium without FBS. A total of $1 \mathrm{ml} 90 \%$ RPMI-1640 supplemented with $10 \%$ FBS was added to the lower chambers. Following incubation for $48 \mathrm{~h}$, the migrating or invading cells were fixed with $4 \%$ paraformaldehyde for $30 \mathrm{~min}$ and subsequently stained with $0.1 \%$ crystal violet solution for $30 \mathrm{~min}$ at room temperature. The stained cells in the lower chamber were counted using an inverted microscope (Nikon Corporation) at a magnification of $\mathrm{x} 400$, to evaluate the invasion or migration ability.

Wound healing assay. A total of $5 \times 10^{5}$ cells in $10 \%$ FBS medium were seeded into 6-well culture plates and cultured to $90 \%$ 
Table II. shRNA sequence for NTF4 and siRNA sequence for Atg5.

Sense $\left(5^{\prime}-3^{\prime}\right)$

Antisense (5'-3')

$\begin{array}{ll}\text { NTF4-sh1 } & \text { GCUGAUAACGCUGAGGAAGTT } \\ \text { NTF4-sh2 } & \text { GCAAGGCCAAGCAGUCCUATT } \\ \text { NTF4-sh3 } & \text { GCUGGCGAUGGAUUCGAAUTT } \\ \text { siAtg5 } & \text { GACGUUGGUAACUGACAAATT }\end{array}$

CUUCCUCAGCGUUAUCAGCTT UAGGACUGCUUGGCCUUGCTT AUUCGAAUCCAUCGCCAGCTT UUUGUCAGUUACCAACGUCTT

NTF4, neurotrophin-4; Atg5, autophagy-associated gene 5.

Table III. Primers for reverse transcription-quantitative PCR analysis.

\begin{tabular}{lll}
\hline Gene & \multicolumn{1}{c}{ Forward primer $\left(5^{\prime}-3^{\prime}\right)$} & \multicolumn{1}{c}{ Reverse primer $\left(5^{\prime}-3^{\prime}\right)$} \\
\hline NTF4 & GTACTTCTTTGAAACCCGCTG & GCAGTGTCAATTCGAATCCATC \\
GAPDH & GGGACCTGACTGACTACCTC & TCATACTCCTGCTTGCTGAT \\
Ecad & AGTCACTGACACCAACGATAAT & ATCGTTGTTCACTGGATTTGTG \\
Vim & AGTCCACTGAGTACCGGAGAC & CATTTCACGCATCTGGCGTTC \\
Snail1 & AAGGATCTCCAGGCTCGAAAG & GCTTCGGATGTGCATCTTGA \\
Beclin-1 & CAAGATCCTGGACCGTGTCA & TGGCACTTTCTGTGGACATCA \\
Atg4b & AGAGCCCGTTTGGATACT & GTCGATGAATGCGTTGAG \\
Atg7 & TGTATAACACCAACACACTCGA & GGCAGGATAGCAAAACCAATAG \\
Vsp34 & GGACCTTCTGACCACGAT & GCAACAGCATAACGCCTC
\end{tabular}

NTF4, neurotrophin-4; Atg5, autophagy-associated gene 5.

confluence. Then, a sterile $200-\mu 1$ micropipette tip was used to scratch the cell monolayer. The cells were cultured in serum-free medium incubated at $37^{\circ} \mathrm{C}$ for $48 \mathrm{~h}$ prior to being visualized using an inverted microscope (LV150N; Nikon Corporation) at a magnification of $\mathrm{x} 200$. The wound areas were quantified using ImageJ software, version 1.8.0 (National Institutes of Health).

Flow cytometric analysis of apoptosis. A total of $2 \times 10^{5}$ cells were collected by centrifugation at room temperature $(800 \mathrm{x} \mathrm{g}$ for $5 \mathrm{~min}$ ) and washed three times with PBS. The samples were resuspended in $100 \mu$ l binding buffer and subsequently stained with $5 \mu \mathrm{l}$ Annexin-V and propidium iodide (PI) for $20 \mathrm{~min}$ at room temperature in the dark. Following staining, an additional $400 \mu \mathrm{l}$ binding buffer was added to resuspend the sample. Apoptotic cells were subsequently analyzed using a flow cytometer (BD Biosciences) and visualized by FlowJo software, version. 7.6.1 (Ashland).

Cell cycle analysis. A total of $1 \times 10^{6}$ cells were collected by centrifugation at room temperature $(800 \mathrm{x}$ g for $5 \mathrm{~min})$, fixed in $70 \%$ ethanol and incubated at $4^{\circ} \mathrm{C}$ overnight. Cells were subsequently stained with PI staining solution for $30 \mathrm{~min}$ at room temperature in the dark before being analyzed by flow cytometry. The fractions of the cells in the G1, S and G2/M phases were calculated using Modfit software (version 5; Verity Software House, Inc.).

Cell proliferation assay. A total of $3 \times 10^{3}$ cells were cultured in 96-well plates in $100 \mu \mathrm{l}$ RPMI-1640 medium. Cell proliferation was assessed via the Cell Counting Kit-8 (CCK-8) kit (Dojindo Molecular Technologies, Inc.) according to the manufacturer's protocol. Briefly, $10 \mu \mathrm{l} \mathrm{CCK-8} \mathrm{solution} \mathrm{was} \mathrm{added} \mathrm{to} \mathrm{each} \mathrm{well}$ of the plate for different incubation times $(0,24,48$ and $72 \mathrm{~h})$ at $37^{\circ} \mathrm{C}$. The absorbance was measured at $450 \mathrm{~nm}$ after $2 \mathrm{~h}$ of incubation.

Colony formation assay. A total of 500 cells were seeded into 6-well plates and incubated at $37^{\circ} \mathrm{C}$. The colony size was observed daily using a microscope until the number of cells in the majority of colonies was $>50$. The medium was subsequently removed, and the cells were stained with $0.2 \%$ crystal violet solution for $30 \mathrm{~min}$ at room temperature. The cells were washed three times with PBS before the colonies were visualized and photographed using a light microscope (77002; Yuyan Instruments Co., Ltd.) at a magnification of $\mathrm{x} 4$. The rate of colony formation was calculated using the following equation: Rate of colony formation $(\%)=($ colony number/500)x100.

Subcutaneous xenografts of nude mice. All experimental procedures were approved by the Institutional Animal Care and Utilization Committee of Fudan University Pudong Animal Experimental Center. The study was conducted according to the Animal Research Reporting In Vivo Experiments guidelines. A total of 14 female Balb/c-nu mice, weighing $20 \pm 3 \mathrm{~g}$ and aged 5 weeks, were purchased from Beijing Vital River Laboratory Animal Technology Co., Ltd. The mice were randomly divided into the HCT116-sh2 and HCT116-scr 

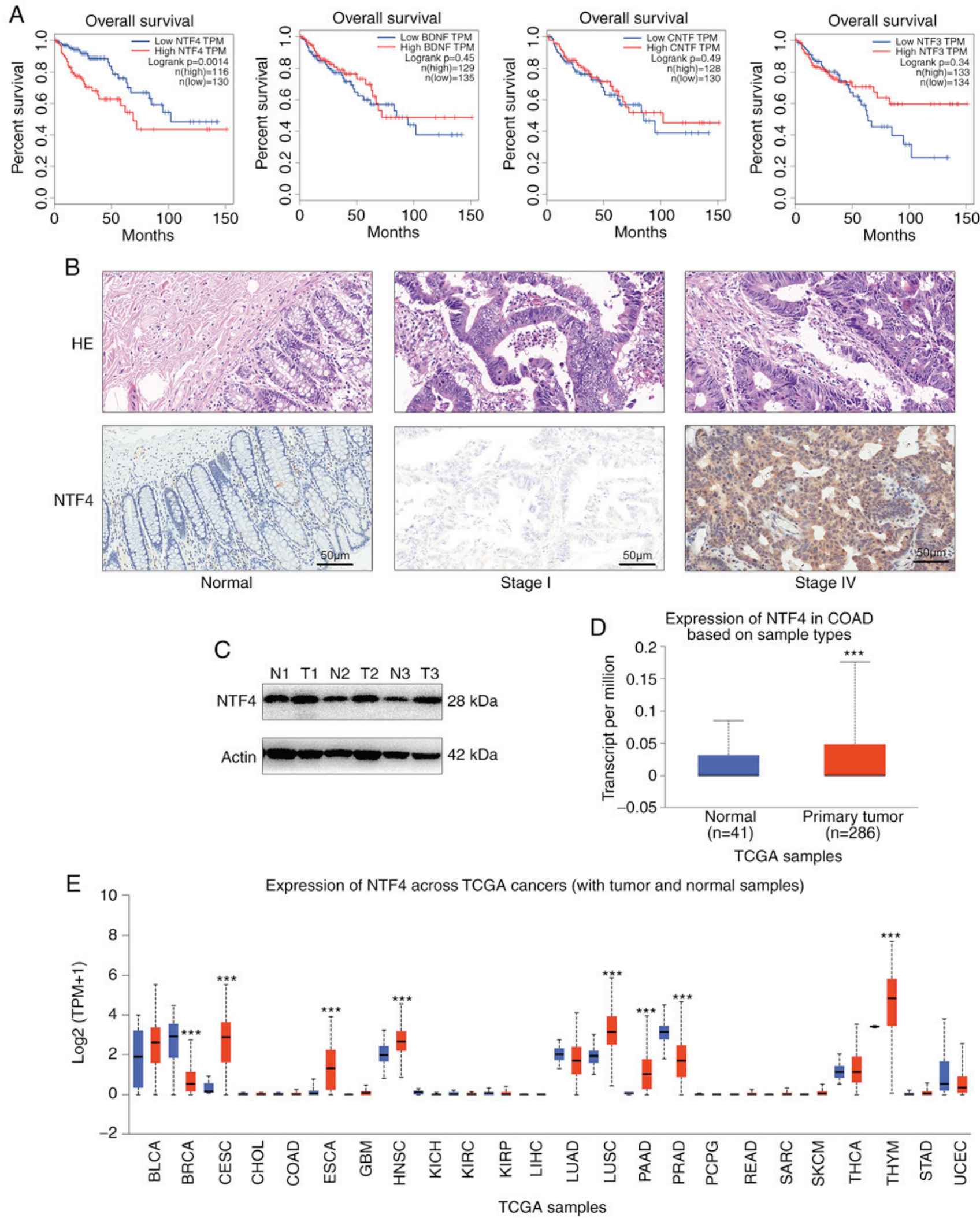

Figure 1. (A) The association between overall survival in patients with CRC and NTF expression was assessed using the GEPIA website tool through Kaplan-Meier analysis. (B) Hematoxylin and eosin (HE) and immunohistochemistry staining of normal tissue and CRC at different stages (magnification, x200). (C) The protein expression levels of NTF4 were detected using western blotting. (D) The expression levels of NTF4 in normal samples and patients with CRC were analyzed using TCGA database. (E) The expression levels of NTF4 in multiple types of cancer were analyzed using TCGA database. NTF4, neurotrophin-4; CRC, colorectal cancer; TCGA, The Cancer Genome Atlas. ${ }^{* * *} \mathrm{P}<0.001$.

groups. A total of $5 \times 10^{6}$ HCT116-sh2 or HCT116-scr cells suspended in $100 \mu$ PBS were injected subcutaneously into the axilla of each mouse. At 1 week after injection, the long (L) and short (S) diameter of the tumors were measured using 
A

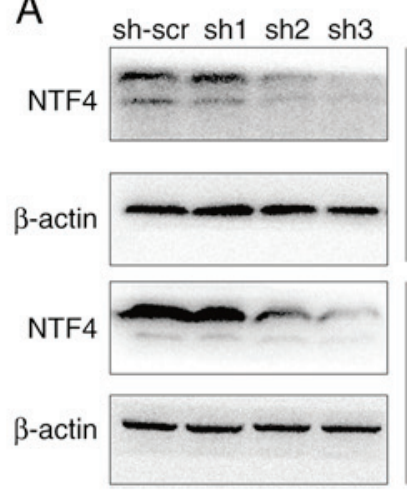

$28 \mathrm{kDa}$

HCT-116

$42 \mathrm{kDa}$

$28 \mathrm{kDa}$

HT-29

$42 \mathrm{kDa}$

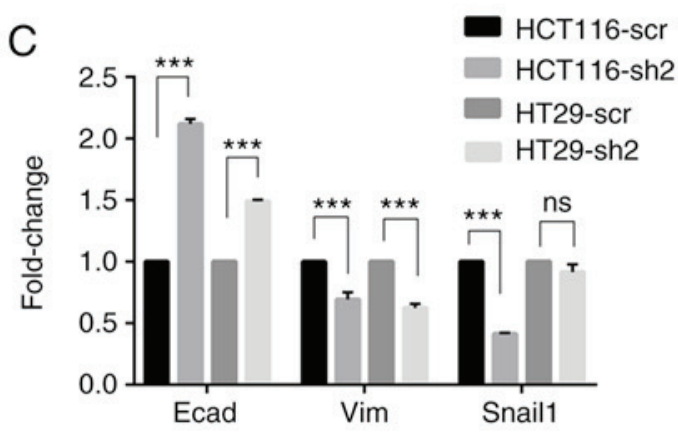

B
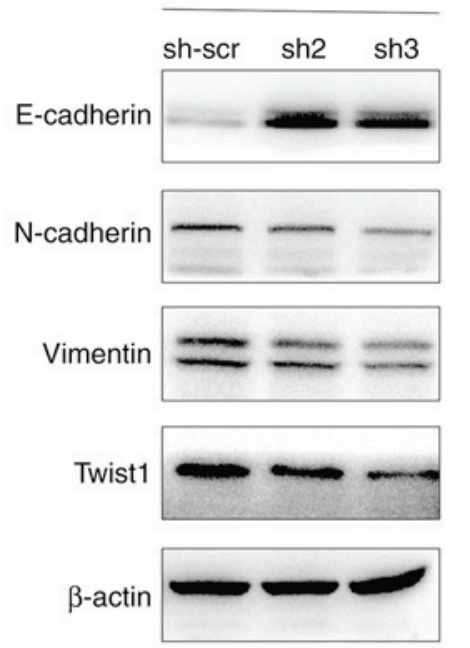
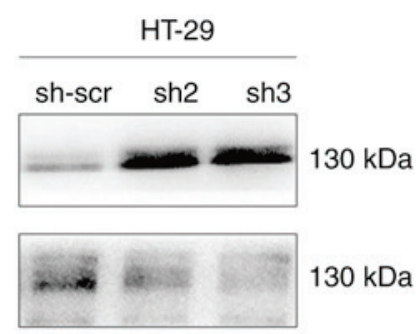

$130 \mathrm{kDa}$

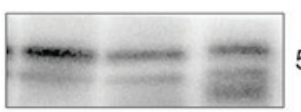

52 kDa

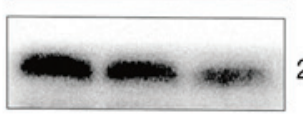

$29 \mathrm{kDa}$

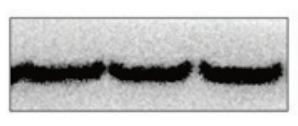

42 kDa
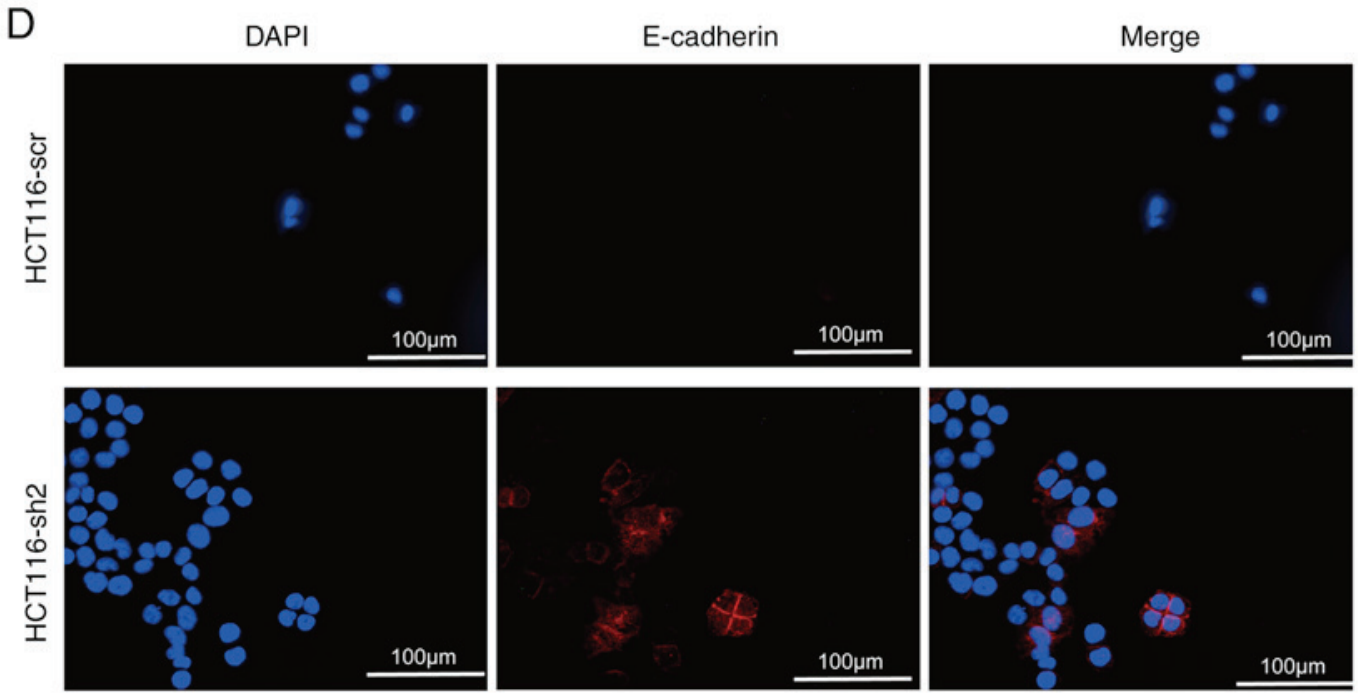

Figure 2. (A) Short hairpin RNA lentivirus transfection in HCT116 and HT-29 cells was confirmed using western blotting. (B) The expression levels of EMT markers in HCT116 and HT-29 cells were detected using western blotting. (C) The mRNA expression levels of EMT markers in HCT116 and HT-29 cells were detected using reverse transcription-quantitative PCR. (D) Localization and expression of E-cadherin in HCT116 cells were detected by immunofluorescence. **** $\mathrm{P}<0.001$. EMT, epithelial-to-mesenchymal transition; NTF4, neurotrophin-4; CRC, colorectal cancer.

vernier calipers every 3 days (tumor volume $=\mathrm{L} \times \mathrm{S}^{2} / 2$ ). The measured tumor volume was used to draw the growth curve of subcutaneous tumors. All mice were sacrificed 3 weeks after injection and the subcutaneous tumors were removed completely.

Statistical analysis. Data are presented as the mean \pm standard deviation and each experiment was performed in triplicate. Significant differences between two groups was performed using a Student's t-test, whereas differences between $>2$ groups were performed using one-way ANOVA, with Tukey's post hoc test for multiple comparisons. $\mathrm{P}<0.05$ was considered to indicate a statistically significant difference.

\section{Results}

NTF4 is upregulated in CRC tissue. Overall survival (OS) according to the expression of NTFs was determined using the GEPIA online tool (http://gepia.cancer-pku.cn/) based on TCGA database via Kaplan-Meier analysis (18). CRC with high expression levels of NTF4 was associated with poor OS (Fig. 1A). To confirm the function of NTF4 in CRC, IHC was performed to detect the expression levels of NTF4. NTF4 was found to be significantly overexpressed in CRC tissue compared with healthy non-tumor mucosa, and advanced CRCs exhibited higher expression levels compared with early-stage CRC samples (Fig. 1B). Western blotting confirmed that NTF4 

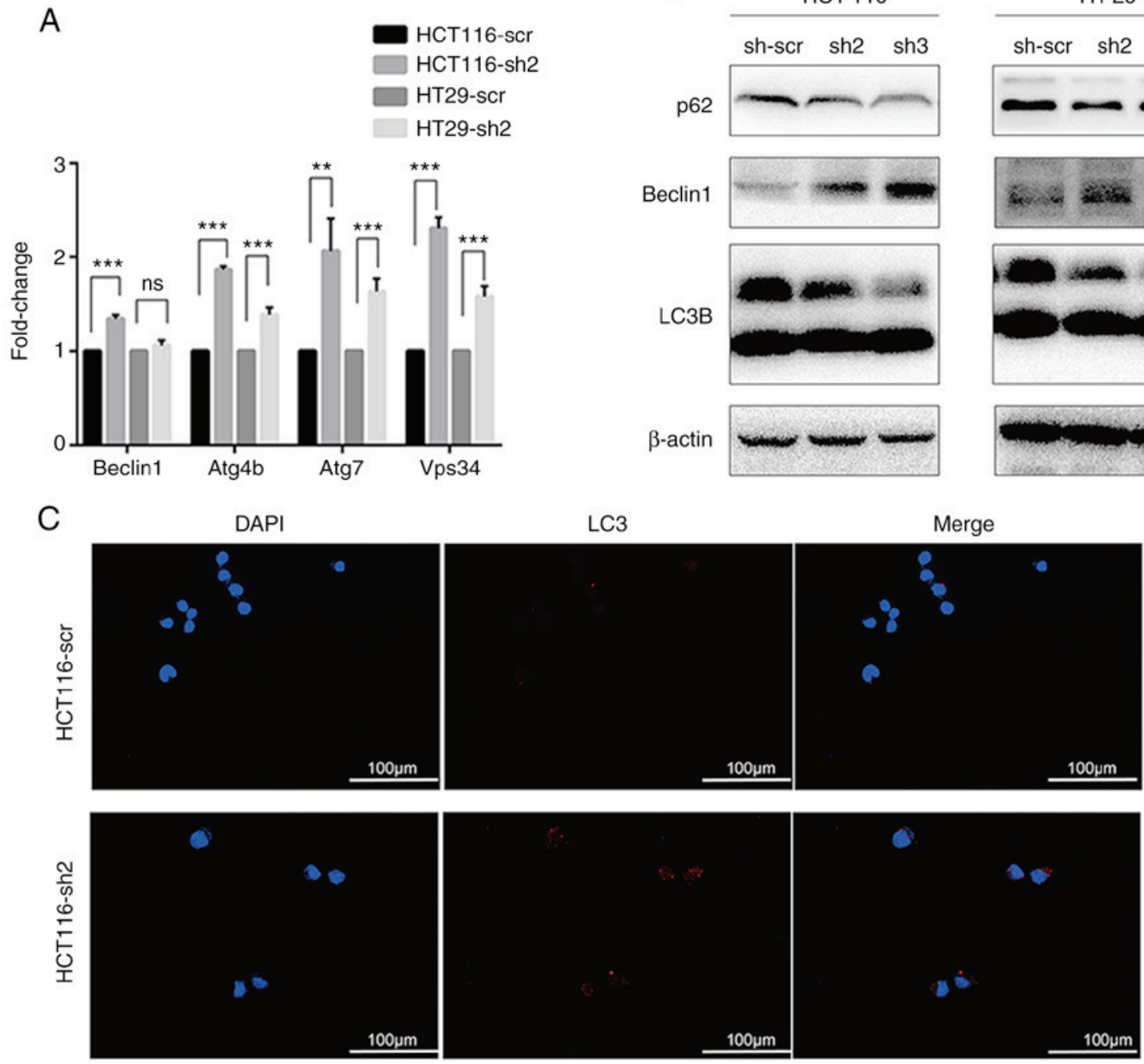

D
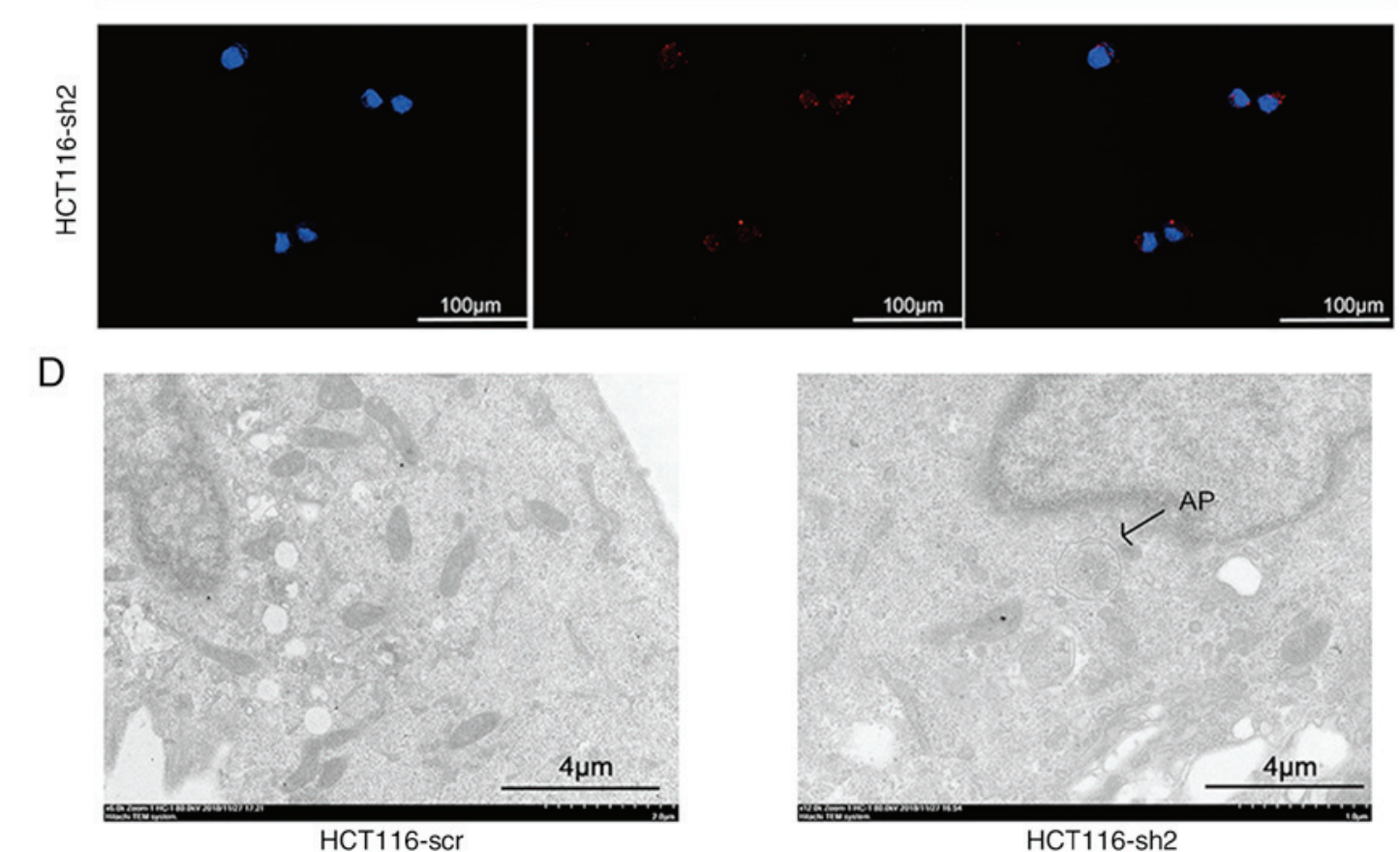

B
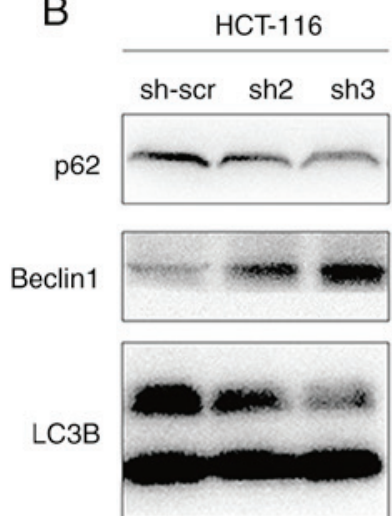

$\beta$-actin
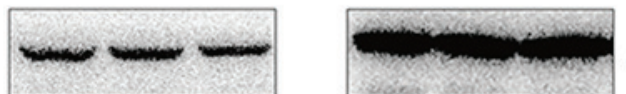

$42 \mathrm{kDa}$
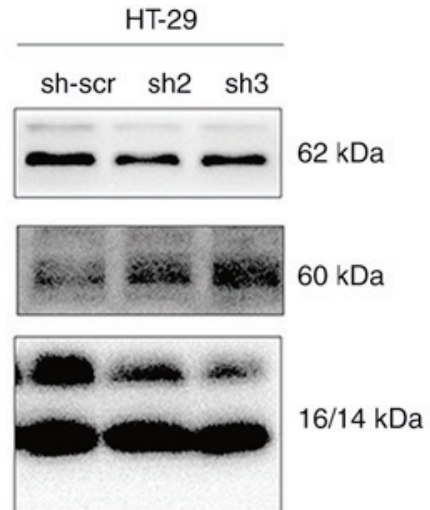

Figure 3. (A) The mRNA expression levels of autophagy-associated genes were detected using reverse transcription-quantitative PCR. (B) The expression levels of autophagy-associated proteins in HCT-116 and HT-29 cells were detected using western blotting. (C) Autophagic flux in HCT-116 cells was detected using immunofluorescence. (D) Visualization of autophagosome (AP; arrow) formation in HCT116 cells using transmission electron microscopy. ${ }^{* *} \mathrm{P}<0.01$ and **** $\mathrm{P}<0.001$.

was upregulated at the protein level in tumor tissue compared with normal tissue (Fig. 1C). Similar results were obtained through analyzing the expression levels of NTF4 in CRC using TCGA database and the Ualcan web tool (http://ualcan.path. uab.edu) (19) (Fig. 1D). In addition, the expression levels of NTF4 were differentially regulated in various other types of cancer, including cervical and breast cancer (Fig. 1E). Overall, the findings suggested that NTF4 may act as a biomarker in multiple types of cancer.

Knockdown of NTF4 inhibits EMT in vitro. To identify an association between NTF4 and EMT, three shRNA lentiviruses targeting NTF4 were infected into HCT-116 and HT-29 cells. Using western blotting, sh 2 and $\operatorname{sh} 3$ were observed to significantly 


\section{A}

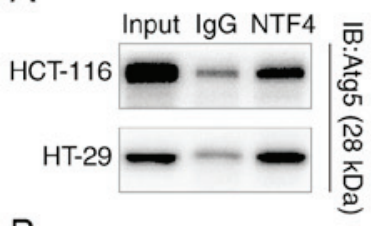

B

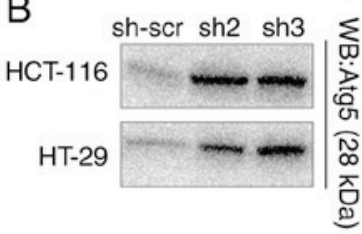

E
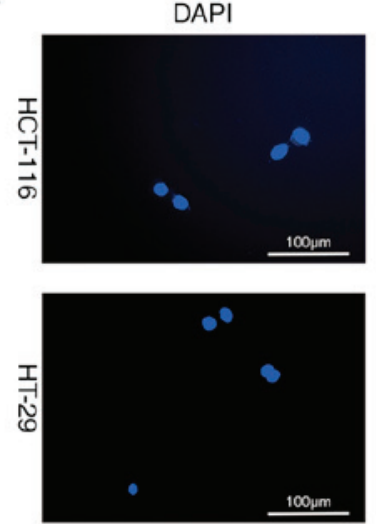
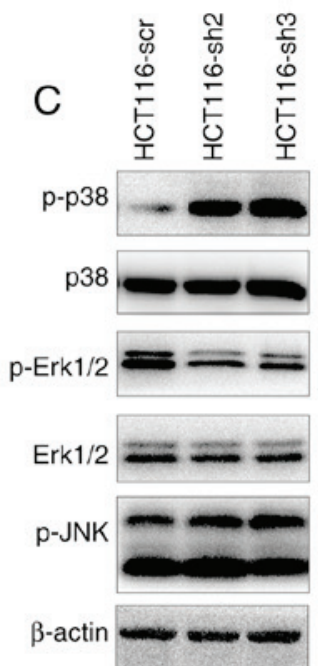

Atg5
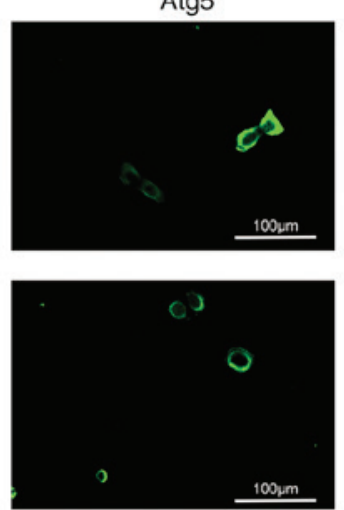
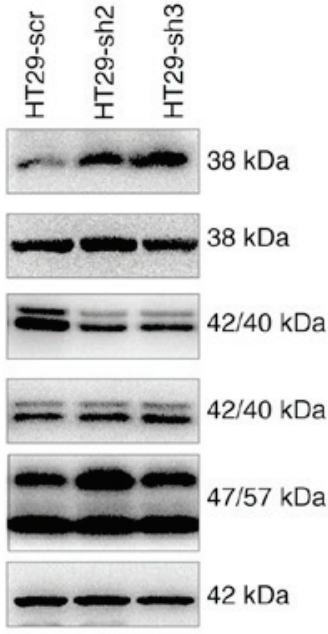

NTF4
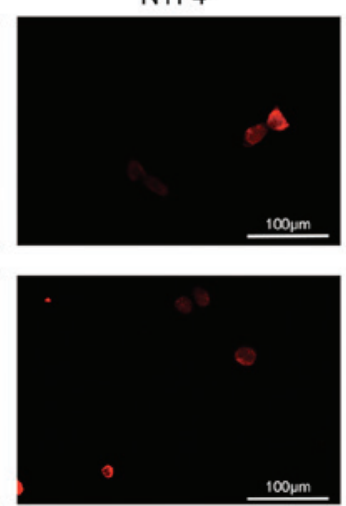
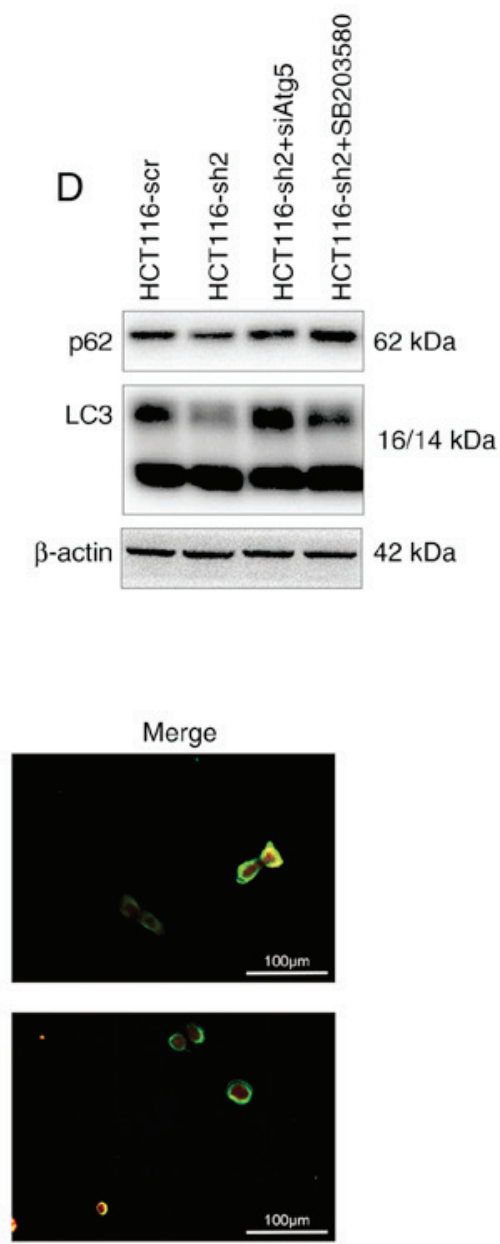

Figure 4. (A) Co-immunoprecipitation analysis between NTF4 and Atg5. (B) The expression levels of Atg5 following knockdown of NTF4 were analyzed using western blotting. (C) The expression levels of 3 MAPK pathway components following the knockdown of NTF4 were detected using western blotting (p38 MAPK, ERK1/2 and JNK). (D) p62 and LC3 expression levels in siAtg5-transfected and p38 MAPK-treated HCT116-sh2 cells were detected using western blotting. (E) Co-localization of Atg5 and NTF4 in HCT-116 and HT-29 cells was detected using immunofluorescence. NTF4, neutrotrophin-4; Atg5, autophagy-associated gene 5; MAPK, mitogen-activated protein kinase; si, small interfering RNA; sh, short hairpin RNA.

reduce the expression levels of NTF4 in both CRC cell lines (Fig. 2A). Several EMT markers were subsequently detected in sh2 and sh3-infected cells. The expression levels of E-cadherin were significantly increased, whereas those of N-cadherin, vimentin and Twist were significantly decreased in both sh2- and sh3-infected cells compared with sh-scr-infected cells (Fig. 2B). RT-qPCR analysis detected results similar to those of western blotting, except that no significant differences in Snail expression levels were identified between HT-29-sh2 and HT-29-scr cells (Fig. 2C). Furthermore, IF was used to identify the localization and expression of the EMT marker E-cadherin in HCT-116 cells. E-cadherin was detected on the cell membrane and cell junctions (Fig. 2D). The expression levels of E-cadherin in HCT116-sh2 cells were significantly increased compared with HCT116-scr (Fig. 2D). These results indicated that the knockdown of NTF4 suppressed EMT in CRC cells.

Knockdown of NTF4 activates autophagy in vitro. To investigate the association between NTF4 and autophagy, mRNA expression levels of autophagy-associated genes were assessed by RT-qPCR. The majority of the autophagy-associated genes were significantly increased in HCT116-sh2 and HT-29-sh2 cells compared with those in HCT116-scr and HT-29-scr cells; however, no significant difference was observed in the expression levels of Beclin-1 between HT-29-sh2 and HT-29-scr cells (Fig. 3A). The expression levels of autophagy-associated proteins were analyzed using western blotting. In both HCT-116 and HT-29 cells, the expression levels of p62 were found to be significantly decreased, whereas Beclin-1 and the LC3II/I ratio were significantly increased in both sh2- and sh3-infected cells compared with sh-scr-infected cells (Fig. 3B). Furthermore, IF was used to detect the autophagic flux in HCT-116 cells. The autophagic flux in HCT116-sh2 cells was significantly increased compared with that in HCT116-scr-infected cells (Fig. 3C). Finally, TEM was performed to observe autophagosome formation (Fig. 3D); autophagosome formation was observed in HCT116-sh2-cells, but not in HCT116-scr-infected cells. These data indicated that the knockdown of NTF4 may activate autophagy in CRC cells.

NTF4 regulates autophagy through interacting with the Atg5 and MAPK pathway. In order to determine the regulatory role of NTF4 in autophagy, several key autophagy-associated molecules and pathways were investigated. Through Co-IP analysis, NTF4 was found to interact with Atg5, an important autophagy regulatory molecule (Fig. 4A). The knockdown of 
A
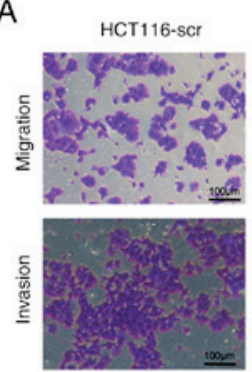

B

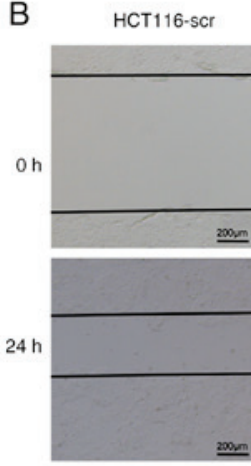

C

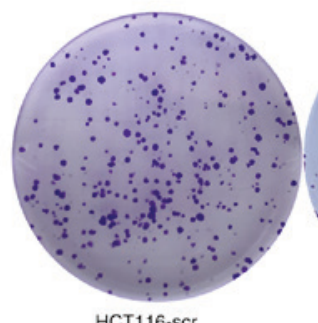

HCT116-scr

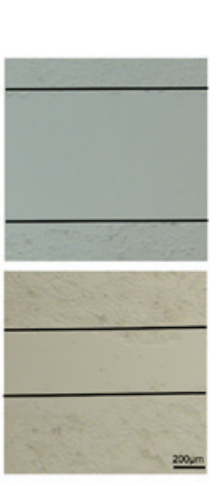

HCT116-scr+CQ
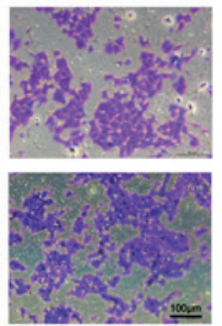

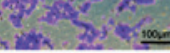

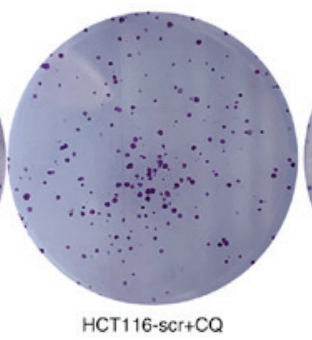

HCT116-scr+CO

HCT116-sh2+CQ
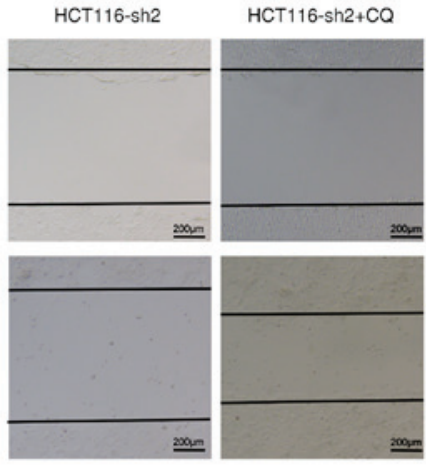

HCT116-sh2
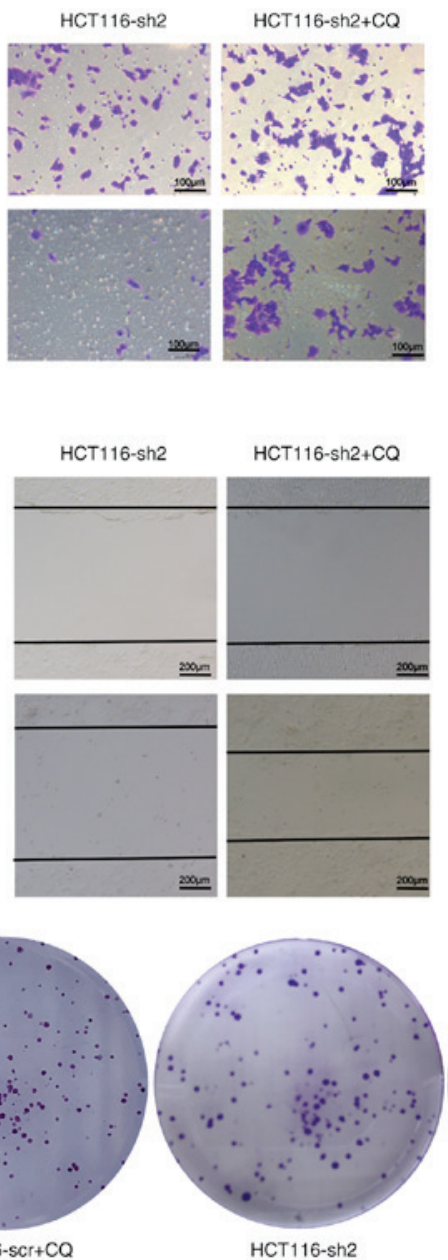

HCT116-sh2
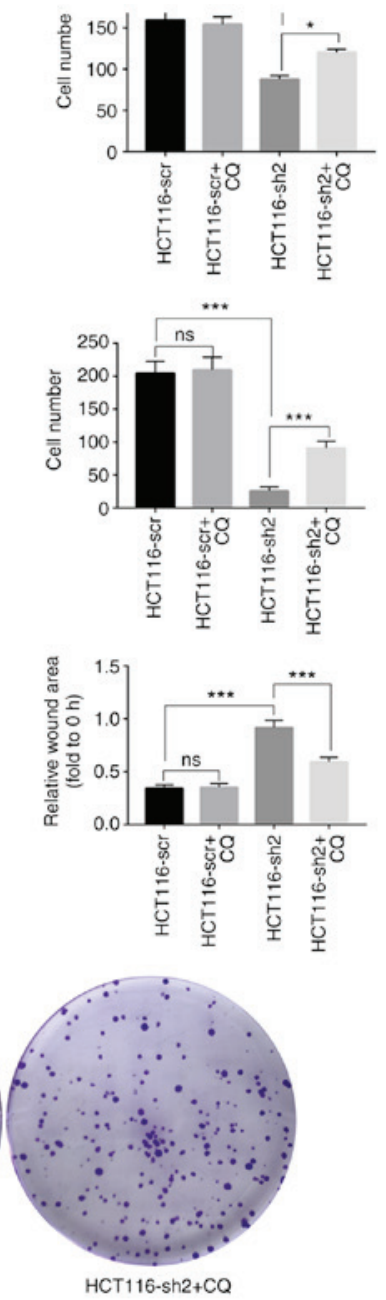

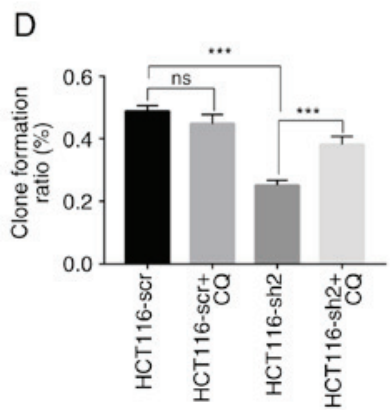

Figure 5. (A) Cell migration and invasion ability was analyzed using Transwell assays. (B) Cell migration ability was analyzed using the wound healing assay. (C) Colony formation assay and (D) ratio of each group. ${ }^{*} \mathrm{P}<0.05,{ }^{* * *} \mathrm{P}<0.001$

NTF4 also increased the expression levels of Atg5 (Fig. 4B). IF identified a significant co-localization between NTF4 and Atg5 in HCT-116 and HT-29 cells (Fig. 4E). In addition, activation of the MAPK pathway was detected by western blotting; p38 MAPK expression levels were significantly upregulated, whereas ERK1/2 expression levels were significantly inhibited in NTF4 knockdown cells (Fig. 4C). Both siAtg5 and the p38 MAPK inhibitor SB203580 (10 $\mu \mathrm{M}$ for $2 \mathrm{~h})$ rescued the decreased expression levels of p62 and increased the LC3 II/I ratio in HCT116-sh2-infected cells (Fig. 4D).

Knockdown of NTF4 inhibits CRC cell invasion, migration, proliferation and colony formation, and promotes cell cycle arrest. In order to determine the association between NTF4-induced autophagy and cell invasion, HCT116-scr and HCT116-sh2-cells were treated with the autophagy inhibitor chloroquine (CQ) and Transwell assays were performed. Cells in the HCT116-sh2 group exhibited reduced migratory and invasive capacity compared with the scramble control group, whereas CQ treatment successfully increased the migratory and invasive ability of the HCT116-sh2 group. In addition, CQ treatment exerted no effect on HCT116-scr. (Fig. 5A). In the wound healing assay, the wound area in the HCT116-sh2 group was wider compared with the scramble control group after $48 \mathrm{~h}$, whereas CQ treatment in the HCT116-sh2 group reduced the size of the wound. Similarly, CQ exerted no effect 

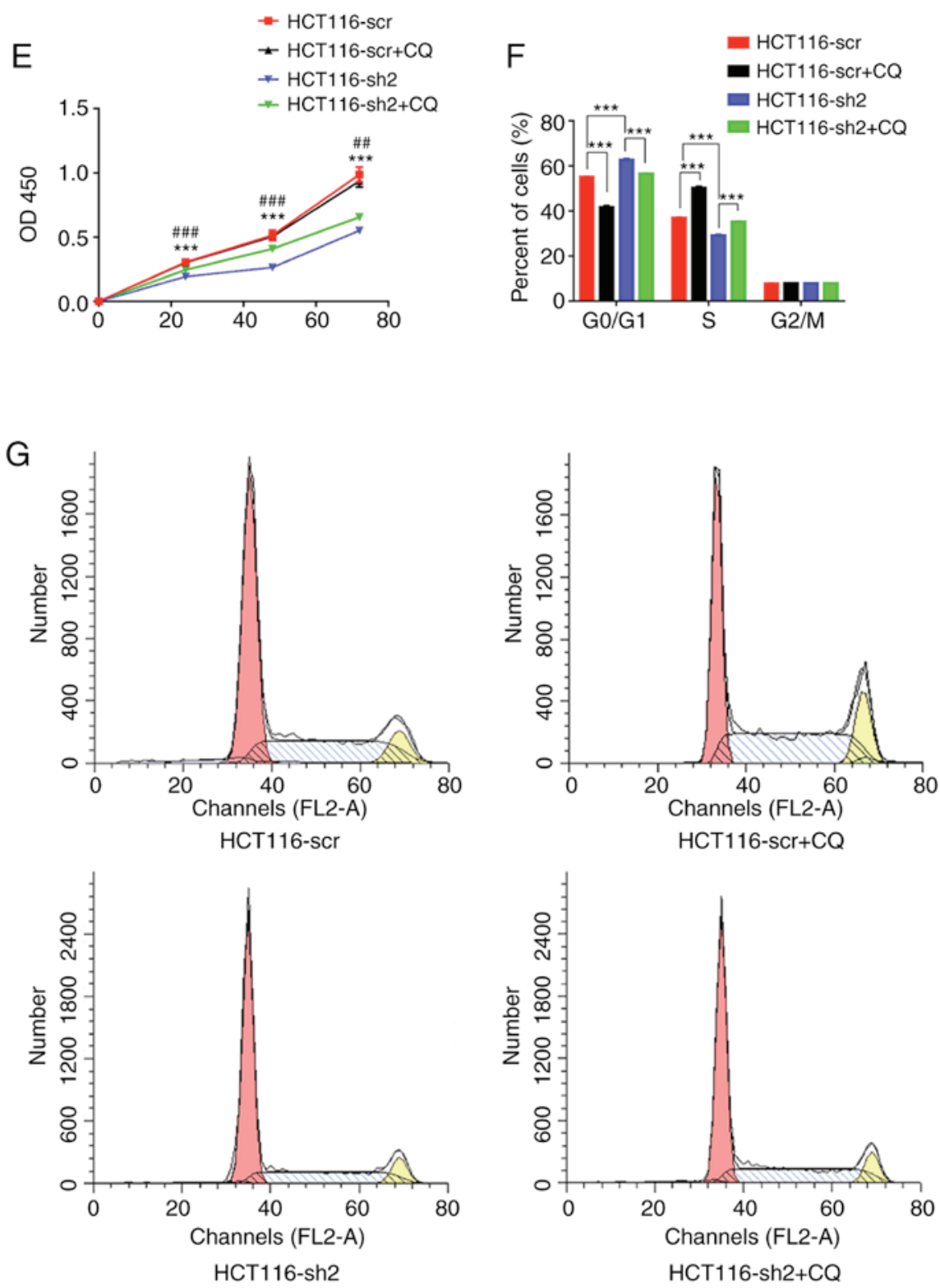

Figure 5. Continued. (E) Cell proliferation of each group was analyzed using a Cell Counting Kit-8 assay. ${ }^{* * *} \mathrm{P}<0.001$, HCT116-sh2 vs. HCT116-scr; ${ }^{\# \#} \mathrm{P}<0.01$, ${ }^{\# \# \# P} \mathrm{P}<0.001, \mathrm{HCT} 116$-sh2 vs. HCT116-sh2 + CQ group. (F and G) Cell cycle analysis of HCT-116 cells using flow cytometry. ${ }^{* * *} \mathrm{P}<0.001$. sh, short hairpin RNA; scr, scramble; $\mathrm{CQ}$, chloroquine.

on HCT116-scr in this assay (Fig. 5B). Collectively, these results indicated that the knockdown of NTF4 may inhibit cell migration and invasion through activating autophagy.

To investigate the association between NTF4-induced autophagy and cell proliferation, CCK-8 and colony formation assays were performed. The knockdown of NTF4 in HCT-116 cells significantly inhibited colony formation, whereas CQ treatment reversed this inhibition (Fig. 5C and D). Similar to colony formation, the proliferation of HCT-116 cells was also inhibited by knockdown of NTF4 and was rescued by CQ treatment. CQ treatment exerted no effect on HCT116-scr in the proliferation and colony formation assays (Fig. 5E). Flow cytometric analysis conducted to determine the effect of NTF4 on the cell cycle revealed that sh2-infected cells had an increased percentage of cells in the G1 phase and a decreased percentage in the $\mathrm{S}$ phase, which indicated that the knockdown of NTF4 promoted cell cycle arrest. CQ treatment significantly rescued cell cycle arrest in the HCT116-sh2 group. However, CQ treatment also reduced cell cycle arrest in HCT116-scr (Fig. 5F and G).

Knockdown of NTF4 suppresses tumor growth in vivo. To investigate the effect of NTF4 in vivo, HCT116-sh2 and HCT116-scr cells were injected into Balb/c-nu mice. At 7 days post-injection, the tumor volume in the HCT116-sh2 group was significantly smaller compared with that in the HCT116-scr group (Fig. 6A and B). This trend was maintained until day 21, where there was a significant difference in the growth rate between the two groups. In addition, the tumor weights within the HCT116-sh2 group were significantly lower compared with those in the HCT116-scr group (Fig. 6C). The expression of the EMT marker E-cadherin and the autophagy marker Atg5 was further investigated using IF. Similar to in vitro studies, the expression of both E-cadherin and Atg5 
A
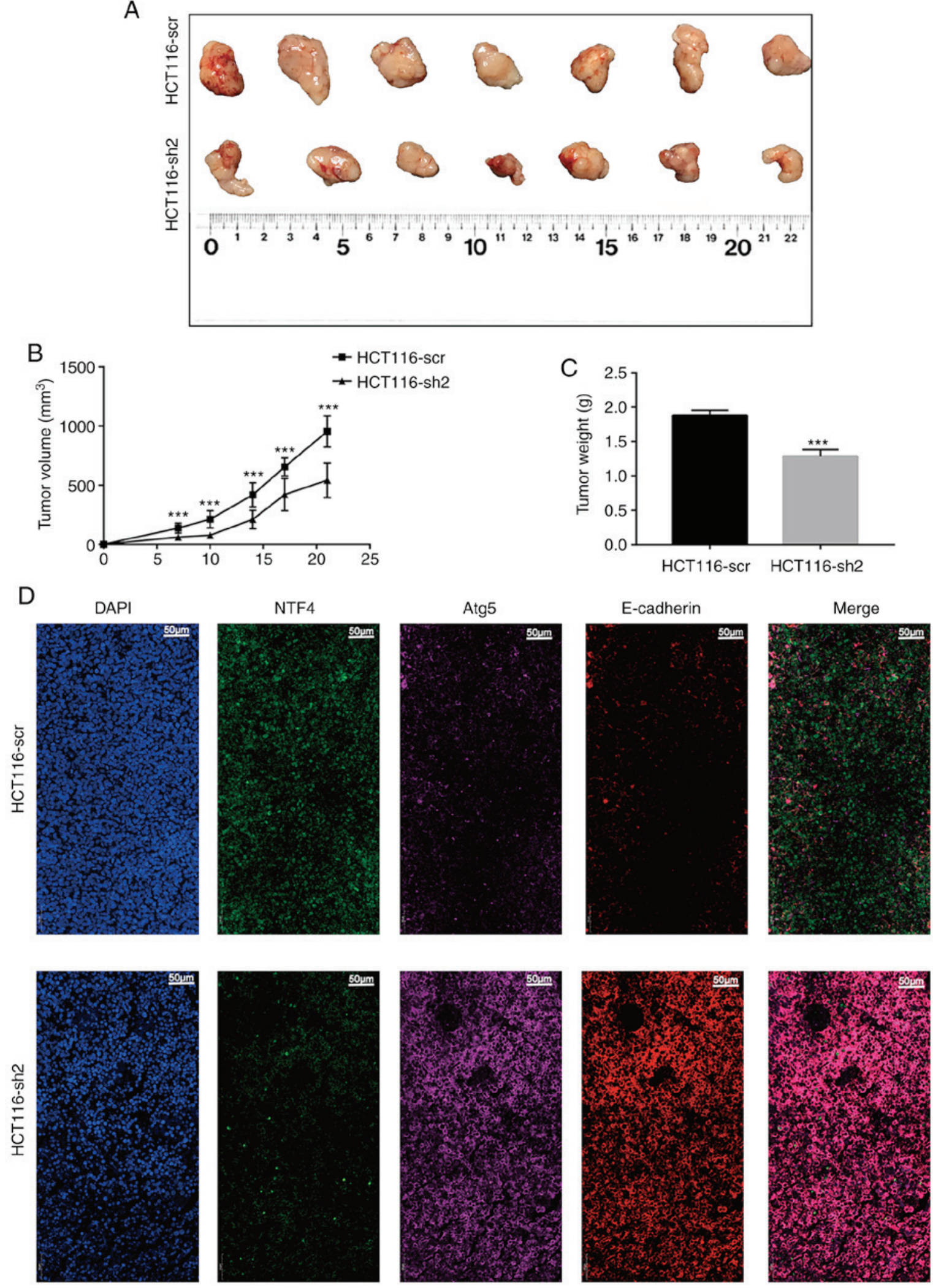

Figure 6. (A) Subcutaneous xenografts in nude mice. (B) Growth curves of xenograft tumors in the HCT116-sh2 and HCT116-scr group. (C) Tumor weights in the HCT116-sh2 and HCT116-scr group. (D) Expression levels and localization of neurotrophin-4, E-cadherin and autophagy-associated gene 5, as detected by immunofluorescence. ${ }^{* * * *} \mathrm{P}<0.001$. sh, short hairpin RNA; scr, scramble.

was significantly increased in HCT11-sh2-derived compared with HCT11-scr-derived xenografts (Fig. 6D). These findings indicated that the knockdown of NTF4 in vivo may also suppress EMT and activate autophagy.

\section{Discussion}

NTF4 encodes the protein NTF4, which is a neurotrophic factor that signals predominantly through the TrkB receptor tyrosine 
kinase. The majority of studies on NTF4 has focused on its functions in neurology and ophthalmology, but rarely on its role in cancer, with the exception of breast cancer, where NTF4 was shown to contribute to cancer cell survival and served as a potential target to inhibit tumor growth (20). Our previous study demonstrated that NTF4 was significantly overexpressed in CRC tissues compared with normal tissues (21). NTF4 was also observed to be associated with tumor progression. EMT is an important mechanism that initiates tumor invasion and migration to promote tumor progression. In addition, previous studies have revealed that autophagy is associated with tumor progression; the dietary intake of urolithin A inhibited the migration of CRC cells and the activity of matrix metalloproteinase-9 through inducing autophagy (22). In another study, RNF216 prevented autophagy in CRC cells through inhibiting the autophagy-associated gene Beclin-1 during nutritional starvation, thus promoting the proliferation and migration of CRC cells (23). Therefore, the aim of the present study was to further investigate these two mechanisms.

Through western blotting, it was confirmed that the sh2 and sh3 lentivirus induced the knockdown of NTF4 expression levels; this significantly increased the expression levels of E-cadherin, whilst decreasing the expression levels of $\mathrm{N}$-cadherin, vimentin and Twist. These results suggested that NTF4 may induce EMT. The knockdown of NTF4 also significantly decreased the expression levels of p62 and increased the expression levels of Beclin-1 and the LC3 II/I ratio. NTF4 was also observed to interact with Atg5, which is an important regulator of autophagy (20). The inhibition of ERK1/2 has previously been demonstrated to regulate the induction of autophagy $(25,26)$. p38 MAPK reportedly plays a dual role in the regulation of autophagy, as both a positive and a negative regulator; in a previous study, p38 MAPK was found to be a contributing factor to oridonin-induced autophagy (27), whereas in another study, the suppression of p38 MAPK promoted necroptotic and autophagic cell death in tumor necrosis factor $\alpha$-treated L929 cells (28). The present study demonstrated that the knockdown of NTF4 increased p38 MAPK and decreased ERK1/2 expression levels, which suggested that the role of NTF4 in the MAPK pathway may be complicated. Furthermore, the knockdown of NTF4 promoted autophagic flux and the formation of autophagosomes, which indicated that the knockdown of NTF4 may activate autophagy through interacting with Atg5 and regulating the MAPK pathway. In addition, the knockdown of NTF4 significantly inhibited HCT-116 cell invasion and migration, which was successfully restored by $\mathrm{CQ}$ treatment; similar results were reported for the proliferation and colony formation assays. It was also observed that the knockdown of NTF4 promoted cell cycle arrest in HCT-116 cells. As the autophagy inhibitor exerted similar effects on both HCT116-scr and HCT-sh2, it was inferred that NTF4 knockdown promoted cell cycle arrest in HCT-116 cells via activating the p38 MAPK pathway. Previous research in vascular smooth muscle cells has demonstrated that Honokiol, an active component in the extracts of Magnolia officinalis, represses cyclin D1/CDK4 and cyclin E/CDK2 complexes to block the cell cycle in the G1 phase (29). Finally, knockdown of NTF4 was observed to significantly inhibit tumor growth in vivo.
However, our research was performed only in HCT-116 and HT-29 cells, and more CRC cell lines must be investigated to verify the findings of the present study. We also aim to investigate the specific mechanism of action of NTF4 in other tumors. In addition, future research will also include other members of the NTF family.

In conclusion, NTF4 was found to be upregulated in CRC and was associated with tumor progression; the knockdown of NTF4 inhibited CRC tumorigenesis, which may be mediated through regulating EMT and autophagy.

\section{Acknowledgements}

Not applicable.

\section{Funding}

The present study was funded by The Academic Leaders Training Program Supported by Pudong Health Bureau of Shanghai (grant no. PWRd2016-05) and the Scientific Research Foundation provided by Pudong Hospital affiliated to Fudan University (grant no. YJ2020-01).

\section{Availability of data and materials}

The datasets generated and/or analyzed during the present study are available from the corresponding author on reasonable request.

\section{Authors' contributions}

YC and ZY designed and performed the experiments; DW contributed to the statistical analysis of the data; and YQ and $\mathrm{ZM}$ contributed to the design of the study. All authors read and approved the final version of the manuscript.

\section{Ethics approval and consent to participate}

The present study was approved by the Ethics Committee of the Shanghai Pudong Hospital and written informed consent was obtained from all participants. All experimental procedures on animals were approved by the Institutional Animal Care and Utilization Committee of Fudan University Pudong Animal Experimental Center. The study was conducted according to the Animal Research Reporting In Vivo Experiments guidelines.

\section{Patient consent for publication}

Not applicable.

\section{Competing interests}

The authors declare that they have no competing interests.

\section{References}

1. Cunningham D, Atkin W, Lenz HJ, Lynch HT, Minsky B Nordlinger B and Starling N: Colorectal cancer. Lancet 375: 1030-1047, 2010

2. Long AG, Lundsmith ET and Hamilton KE: Inflammation and colorectal Cancer. Curr Colorectal Cancer Rep 13: 341-351, 2017. 
3. Yatsuoka T, Nishimura Y, Sakamoto H, Tanaka Y and Kurozumi M: Lymph node metastasis of colorectal cancer with submucosal invasion. Gan To Kagaku Ryoho 40: 2041-2043, 2013 (In Japanese).

4. Shi Y, Huang XX, Chen GB, Wang Y, Zhi Q, Liu YS, Wu XL, Wang LF, Yang B, Xiao CX, et al: Dragon (RGMb) induces oxaliplatin resistance in colon cancer cells. Oncotarget 7: 48027-48037, 2016.

5. Minichiello L, Casagranda F, Tatche RS, Stucky CL, Postigo A, Lewin GR, Davies AM and Klein R: Point mutation in trkB causes loss of NT4-dependent neurons without major effects on diverse BDNF responses. Neuron 21: 335-345, 1998.

6. Shen Y, Inoue N and Heese K: Neurotrophin-4 (ntf4) mediates neurogenesis in mouse embryonic neural stem cells through the inhibition of the signal transducer and activator of transcription-3 (stat3) and the modulation of the activity of protein kinase B. Cell Mol Neurobiol 30: 909-916, 2010.

7. Lamouille S, Xu J and Derynck R: Molecular mechanisms of epithelial-mesenchymal transition. Nat Rev Mol Cell Biol 15: 178-196, 2014

8. Morrison CD, Parvani JG and Schiemann WP: The relevance of the TGF- $\beta$ Paradox to EMT-MET programs. Cancer Lett 341: 30-40, 2013.

9. Sánchez-Tilló E, Liu Y, de Barrios O, Siles L, Fanlo L, Cuatrecasas M, Darling DS, Dean DC, Castells A and Postigo A: EMT-activating transcription factors in cancer: Beyond EMT and tumor invasiveness. Cell Mol Life Sci 69 3429-3456, 2012

10. Yang Z, Wu D, Chen Y, Min Z and Quan Y: GRHL2 inhibits colorectal cancer progression and metastasis via oppressing epithelial-mesenchymal transition. Cancer Biol Ther 20: 1195-1205, 2019

11. Galluzzi L, Baehrecke EH, Ballabio A, Boya P, Bravo-San Pedro JM, Cecconi F, Choi AM, Chu CT, Codogno P Colombo MI, et al: Molecular definitions of autophagy and related processes. Embo J 36: 1811-1836, 2017.

12. Ouyang L, Shi Z, Zhao S, Wang FT, Zhou TT, Liu B and Bao JK: Programmed cell death pathways in cancer: A review of apoptosis, autophagy and programmed necrosis. Cell Prolif 45: 487-498, 2012.

13. Sato K, Tsuchihara K, Fujii S, Sugiyama M, Goya T, Atomi Y, Ueno T, Ochiai A and Esumi H: Autophagy is activated in colorectal cancer cells and contributes to the tolerance to nutrient deprivation. Cancer Res 67: 9677-9684, 2007.

14. Huang S and Sinicrope FA: Celecoxib-induced apoptosis is enhanced by ABT-737 and by inhibition of autophagy in human colorectal cancer cells. Autophagy 6: 256-269, 2010.

15. Zhang H, Tang J, Li C, Kong J, Wang J, Wu Y, Xu E and Lai M: MiR-22 regulates 5-FU sensitivity by inhibiting autophagy and promoting apoptosis in colorectal cancer cells. Cancer Lett 356 781-790, 2015

16. Livak KJ and Schmittgen TD: Analysis of relative gene expression data using real-time quantitative PCR and the 2(-Delta Delta C(T)) method. Methods 25: 402-408, 2001.
17. Yang Z, Yu W, Huang R, Ye M and Min Z: SIRT6/HIF-1 $\alpha$ axis promotes papillary thyroid cancer progression by inducing epithelial-mesenchymal transition. Cancer Cell Int 19: 17, 2019.

18. Tang Z, Li C, Kang B, Gao G, Li C and Zhang Z: GEPIA: A web server for cancer and normal gene expression profiling and interactive analyses. Nucleic Acids Res 45: W98-W102, 2017.

19. Chandrashekar DS, Bashel B, Balasubramanya SAH,Creighton CJ, Ponce-Rodriguez I, Chakravarthi BVSK and Varambally S: UALCAN: A portal for facilitating tumor subgroup gene expression and survival analyses. Neoplasia 19: 649-658, 2017.

20. Vanhecke E, Adriaenssens E, Verbeke S, Meignan S, Germain E, Berteaux N, Nurcombe V, Le Bourhis X and Hondermarck H: Brain-derived neurotrophic factor and neurotrophin-4/5 are expressed in breast cancer and can be targeted to inhibit tumor cell survival. Clin Cancer Res 17: 1741-1752, 2011.

21. Yang Z, Chen Y, Wu D, Min Z and Quan Y: Analysis of risk factors for colon cancer progression. Onco Targets Ther 12: 3991-4000, 2019

22. Zhao W, Shi F, Guo Z, Zhao J, Song X and Yang H: Metabolite of ellagitannins, urolithin A induces autophagy and inhibits metastasis in human sw620 colorectal cancer cells. Mol Carcinog 57: 193-200, 2018.

23. Wang H, Wang Y, Qian L, Wang X, Gu H, Dong X, Huang S, Jin M, Ge H, Xu C and Zhang Y: RNF216 contributes to proliferation and migration of colorectal cancer via suppressing BECN1-dependent autophagy. Oncotarget 7: 51174-51183, 2016.

24. Yousefi S, Perozzo R, Schmid I, Ziemiecki A, Schaffner T, Scapozza L, Brunner T and Simon HU: Calpain-mediated cleavage of Atg 5 switches autophagy to apoptosis. Nat Cell Biol 8: 1124-1132, 2006.

25. Shinojima N, Yokoyama T, Kondo Y and Kondo S: Roles of the Akt/mTOR/p70S6K and ERK1/2 signaling pathways in curcumin-induced autophagy. Autophagy 3: 635-637, 2007.

26. Wang RC, Wei Y, An Z, Zou Z, Xiao G, Bhagat G, White M, Reichelt J and Levine B: Akt-mediated regulation of autophagy and tumorigenesis through beclin 1 phosphorylation. Science 338: 956-959, 2012

27. Cui Q, Tashiro S, Onodera S, Minami M and Ikejima T: Oridonin induced autophagy in human cervical carcinoma hela cells through ras, JNK, and P38 regulation. J Pharmacol Sci 105: 317-325, 2007.

28. Ye YC, Yu L, Wang HJ, Tashiro S, Onodera S and Ikejima T: TNF $\alpha$-induced necroptosis and autophagy via supression of the p38-NF-кB survival pathway in L929 ells. J Pharmacol Sci 117: 160-169, 2011.

29. Lee B, Kim $\mathrm{CH}$ and Moon SK: Honokiol causes the p21WAF1-mediated G(1)-phase arrest of the cell cycle through inducing p38 mitogen activated protein kinase in vascular smooth muscle cells. FEBS Lett 580: 5177-5184, 2006.

This work is licensed under a Creative Commons Attribution-NonCommercial-NoDerivatives 4.0 International (CC BY-NC-ND 4.0) License. 